\title{
Docência universitária: de bacharel a professor nos cursos de Ciência da Computação e Sistemas da Informação
}

\author{
University teaching: from bachelor to professor in Computer \\ Science and Information Systems courses
}
Docencia universitaria: de licenciado a profesor en cursos de Informática y Sistemas de Información

\author{
Fernanda Quaresma da Silva ${ }^{1}$ \\ Geovana Ferreira Melo²
}

\author{
${ }^{1}$ Mestre em Educação. Universidade Federal de Uberlândia. \\ Uberlândia, Minas Gerais, Brasil. Orcid: https://orcid.org/0000-0002- \\ 1500-9230. E-mail: fernandalauper@gmail.com \\ 2 Pós-doutora em Educação. Universidade Federal de Uberlândia. \\ Uberlândia, Minas Gerais, Brasil. Orcid: https://orcid.org/0000-0001- \\ 8406-6223. E-mail: geovana.melo@gmail.com
}

Recebido para publicação em: 4.5.2021

Aprovado em: 13.7.2021

\section{Resumo}

Este texto é parte de uma pesquisa que analisou o aprendizado da docência de professores bacharéis dos cursos de Ciência da Computação e Sistemas de Informação da Universidade Federal de Uberlândia (UFU). Como ocorre o aprendizado da docência de professores bacharéis nos referidos cursos? Quais seus percursos formativos e quais as contribuições da formação para o desenvolvimento da identidade profissional desses docentes? Quais as principais dificuldades enfrentadas pelos professores dos cursos citados no exercício do magistério? A análise dos dados obtidos indica que os saberes docentes são mobilizados nas próprias práticas, com prevalência dos saberes da experiência, e a identidade profissional é construída a partir das referências de docência. Nesse sentido, reafirmamos a importância de políticas institucionais de formação e desenvolvimento profissional docente que contribuam para o fortalecimento de uma pedagogia universitária que valorize o ensino de graduação e a profissionalização docente.

Palavras-chave: docência universitária; professor bacharel; identidade profissional.

\section{Abstract}

This paper is part of a research that analyzed the teaching learning experience of professors with degrees in Computer Science and Information Systems at the Federal University of Uberlândia (UFU). How does bachelor's degree professors learn to teach in these courses? What are their training paths and what are the contributions of training to the development of the professional identity of these teachers? What are the main 
difficulties faced by the teachers of these courses in the exercise of teaching? The analysis of the data obtained indicates that the teaching knowledge is mobilized in the teaching practices themselves, with a prevalence of knowledge from experience, and the professional identity is built from the teaching references. In this sense, we reaffirm the importance of institutional policies for teacher training and professional development that contribute to the strengthening of a university pedagogy that values undergraduate teaching and professionalization or professors.

Keywords: university teaching; bachelor teacher; professional identity.

\section{Resumen}

Este texto es parte de una investigación que analizó la experiencia de enseñanzaaprendizaje de profesores con títulos en Informática y Sistemas de Información de la Universidad Federal de Uberlândia (UFU). ¿Cómo aprenden los profesores licenciados a enseñar en estos cursos? ¿Cuáles son sus trayectorias formativas y cuáles son las aportaciones de la formación al desarrollo de la identidad profesional de estos docentes? ¿Cuáles son las principales dificultades que enfrentan los docentes de estos cursos en el ejercicio de la docencia? El análisis de los datos obtenidos indica que el conocimiento docente se moviliza en las propias prácticas docentes, con un predominio del conocimiento desde la experiencia, y la identidad profesional se construye a partir de los referentes docentes. En este sentido, reafirmamos la importancia de las políticas institucionales para la formación y el desarrollo profesional docente que contribuyan al fortalecimiento de una pedagogía universitaria que valore la docencia de pregrado y la profesionalización docente.

Palabras clave: docencia universitaria; profesor licenciado; identidad profesional.

\section{Introdução}

Este texto é parte de uma pesquisa realizada nos cursos de Ciência da Computação e Sistemas de Informação, teve início a partir de debates no Grupo de Estudos e Pesquisas sobre Docência na Educação Básica e Superior (GEPDEBS), no qual identificamos que são muitos os desafios enfrentados pelos docentes que atuam nas universidades. No entanto, grande parte desses estudos se refere aos cursos de licenciatura, que, apesar de terem em suas matrizes curriculares disciplinas voltadas para a formação docente, ainda apresentam fragilidades do ponto de vista teórico-metodológico nos processos formativos.

Nas pesquisas sobre a docência no ensino superior, é possível observar que muitos docentes que atuam nos cursos de licenciatura se envolvem quase que prioritariamente no desenvolvimento de pesquisas acadêmicas, e por vezes conhecimentos profissionais necessários à docência não constituem foco dos processos de formação.

Em meu trabalho como supervisora de estágio curricular de discentes dos cursos de bacharelado da Universidade Federal de Uberlândia, especificamente de Ciência da 
Computação e Sistemas de Informação, senti-me instigada a aprofundar a compreensão a respeito dos processos de formação docente dos professores que têm sua formação inicial em cursos de bacharelado. Constatei, por meio de experiências diversas e estudos realizados no âmbito do GEPDEBS, que os objetivos desses cursos, conforme seus projetos pedagógicos, é formar profissionais para o mercado de trabalho e, em grande medida, alinhados a perspectivas formativas pautadas na racionalidade técnica, uma vez que a universidade brasileira, historicamente, profissionaliza.

Sendo assim, partimos dos seguintes questionamentos: como ocorre

Os objetivos desses

cursos, conforme

seus projetos

pedagógicos, é

formar profissionais

para o mercado de trabalho o aprendizado da docência dos professores bacharéis dos cursos de Ciência da Computação e Sistemas de Informação? Quais são seus percursos formativos e quais as contribuições da formação para o desenvolvimento da identidade profissional desses docentes? Quais as principais dificuldades enfrentadas por professores bacharéis dos referidos cursos ao assumirem a docência na universidade? Dessa forma, o objetivo geral da pesquisa foi investigar como ocorre o aprendizado da docência dos professores que atuam nesses cursos na Universidade Federal de Uberlândia.

Para alcançar esse objetivo, fez-se necessário: compreender os percursos formativos dos professores bacharéis e as práticas pedagógicas que contribuíram para sua atuação docente na universidade; analisar as contribuições dos processos formativos para o desenvolvimento da identidade profissional; investigar as principais dificuldades enfrentadas pelos professores bacharéis ao assumirem a docência na educação superior; e contribuir para ampliar os debates no campo da docência universitária. Além de compreender como se constituíram os processos formativos dos docentes bacharéis, foi necessário conhecer suas trajetórias profissionais e familiares e suas experiências como docentes e discentes, ou seja, todos os fatores que os impulsionaram e motivaram a se tornar um docente universitário, bem como compreender sua práxis pedagógica. Dessa maneira, consideramos nos aproximar do objeto da pesquisa.

Para Paulo Netto (2011, p. 45), "o conhecimento concreto do objeto é o conhecimento das suas múltiplas determinações - tanto mais se reproduzem as determinações de um objeto, tanto mais o pensamento reproduz a sua riqueza (concreção) real". Assim, compreender como ocorreu a trajetória formativa dos docentes bacharéis, não apenas como profissionais, mas como sujeitos sociais, permitirá interpretarmos a relação dialógica das transformações e ressignificações pela qual esses profissionais constroem suas práticas pedagógicas.

A pesquisa, de cunho exploratório, foi desenvolvida em uma abordagem qualitativa que, de acordo com Neves (1996), é direcionada, pois obtém os dados mediante contato direto e interativo do pesquisador com o objeto de estudo. Neves (1996) afırma que a abordagem qualitativa traz contribuições ao trabalho de pesquisa, pois envolve procedimentos de cunho racional e intuitivo, capazes de contribuir para uma melhor compreensão dos fenômenos. 
Os dados foram obtidos por meio de questionário, por considerarmos que esse instrumento alcançaria a maior parte dos docentes participantes, viabilizando apreender suas percepções e concepções a respeito de suas trajetórias formativas e profissionais no magistério universitário. O questionário foi elaborado considerando a necessidade de questões fechadas e abertas, conforme os objetivos da pesquisa.

O percurso metodológico da pesquisa foi delineado tendo em vista responder os questionamentos que balizaram a pesquisa, assim enunciados: como ocorre o aprendizado da docência de professores bacharéis? Quais são seus percursos formativos? Quais as principais dificuldades enfrentadas no exercício do magistério? Pautamo-nos em Cervo, Bervian e Silva (2007, p. 27), que afirmam: "[...] nas ciências, entende-se por método o conjunto de processos empregados na investigação e na demonstração da verdade. Não se inventa um método; ele depende, fundamentalmente, do objeto da pesquisa."

O método não é o modelo, fórmula ou receita que, uma vez aplica$\mathrm{da}$, colhe, sem margem de erro, os resultados previstos ou desejados. É apenas um conjunto ordenado de procedimentos que se mostraram eficientes, ao longo da história, na busca do saber. 0 método científico é, pois, um instrumento de trabalho. O resultado depende de seu usuário (CERVO; BERVIAN; SILVA, 2007, p. 28).

Ao aprofundarmos temas relacionados à docência, ressaltamos que a trajetória percorrida é rica de experiências e que esse processo só pode ser compreendido em contexto, considerando a historicidade do objeto. Paulo Netto afırma que o conhecimento teórico é o conhecimento do objeto, ou seja, de sua estrutura e dinâmica, tal como ele é em si mesmo, na sua existência real, e que isso independe dos desejos, aspirações e representações do pesquisador. Ainda, que "[...] pela teoria o sujeito reproduz em seu pensamento a estrutura e a dinâmica do objeto que pesquisa”, e esta será a mais verdadeira e correta quanto mais fiel o sujeito for ao objeto (PAULO NETTO, 2011, p. 21). Independentemente de nossos objetivos e/ou experiências vivenciadas ao longo de nosso percurso de investigação, buscamos nos aproximar de nosso objeto de estudo e apresentar os resultados na sua originalidade e concretude.

Dessa forma, vislumbramos esses professores como sujeitos sociais que mobilizam saberes específicos, provenientes de fontes diversas, para realizar a prática pedagógica. Para Marquez e Pimenta (2015, p. 151),

Os saberes da pedagogia e da didática possibilitam a construção de uma visão de totalidade, essencial à formação de profissionais capazes de realizar análises e elaborar encaminhamentos no sentido de possibilitar a democratização do conhecimento, a superação do tratamento fragmentado do saber escolar e a articulação da ação dos diferentes docentes rumo à concretização de um projeto formativo. Desprovida desses saberes, a ação do professor se reduz ao trabalho com um campo disciplinar de maneira desvinculada de uma intencionalidade pedagógica mais ampla, o que conduz à descaracterização da natureza da docência. 
A pesquisa partiu do estudo documental em fontes da própria instituição e dos cursos, lócus de nosso estudo. E também de legislações atinentes, que nos permitiram contextualizar o tema investigado frente às múltiplas determinações e condicionantes que interferem na construção de interpretações sobre o objeto de pesquisa. De acordo com Bardin (1977, p. 45-46), a análise documental é defınida como:

[...] uma operação ou um conjunto de operações visando representar o conteúdo de um documento sob uma forma diferente da original, a fim de facilitar num estado ulterior, a sua consulta e referenciação. [...] Enquanto tratamento da informação contida nos documentos acumulados, a análise documental tem por objetivo dar forma conveniente e representar de outro modo essa informação, por intermédio de procedimentos de transformação.

A análise documental contribui para elucidar questões e aspectos que podem contribuir para a melhor compreensão do objeto, pois tem como propósito, conforme indica Bardin (1977, p. 45-46), atingir "[...] o armazenamento sob uma forma variável e a facilitação do acesso ao observador, de tal forma que esse obtenha o máximo de informação (aspecto quantitativo), com o máximo de pertinência (aspecto qualitativo). A análise documental é, portanto, uma fase preliminar da constituição de um serviço de documentação ou de um banco de dados".

Bardin (1977) sugere a leitura flutuante como proposta de análise. A partir de uma primeira leitura flutuante podem surgir intuições que convenham ser formuladas em hipóteses.

A partir de uma

primeira leitura

flutuante podem

surgir intuições

que convenham

ser formuladas

em hipóteses

Analisamos diferentes pesquisas empreendidas nos últimos cinco anos que investigaram temas semelhantes. Esses estudos foram localizados nas principais plataformas de dados de programas de pós-graduação credenciados pela Coordenação de Aperfeiçoamento de Pessoal de Nível Superior (Capes). Também foi consultada bibliografia que aborda o desenvolvimento profissional docente, a profissão docente, a legislação brasileira relacionada ao papel da universidade e ao magistério no ensino superior, entre outros temas relacionados.

Dessa forma, foi possível construir o corpus da pesquisa, constituído por informações oriundas da pesquisa teórica, documental e de fontes empíricas obtidas por meio dos questionários respondidos pelos docentes que atuam nos referidos cursos. De acordo com Cervo, Bervian e Silva (2007, p. 53): “O questionário é a forma mais usada para coletar dados, pois possibilita medir com mais exatidão o que se deseja. Todo questionário deve ter natureza impessoal para assegurar uniformidade na avaliação de uma situação para outra."

Os questionários foram encaminhados por e-mail aos professores e foi realizado por nós um recorte, com o intuito de privilegiar os professores efetivos dos referidos cursos. Ao todo, 71 docentes foram contatados, mas obtivemos resposta de apenas 15. O questionário trazia 34 questões em modelo misto, sendo 17 fechadas e 21 abertas. Parte delas buscou informações sobre a identificação dos docentes 
(idade, gênero, formação acadêmica etc.). Outras eram referentes ao percurso profissional (experiências anteriores, tempo de atuação no magistério, curso em que já atuou como docente, tempo de ingresso no mercado trabalho, qual(is) pesquisa(s) desenvolveu no último ano, estágios que supervisionou etc.). Parte das questões, por nós consideradas como as mais interessadas, direcionaram as perguntas, a maioria delas abertas, para a prática pedagógica. Buscamos entender como essa prática é exercida e a partir de quais referências (os cursos de formação que fizeram, os professores que os marcaram, as troca entre pares, as crenças, entre outros aspectos).

\section{0 contexto das universidades e suas finalidades}

A partir dos estudos elencados e das reflexões que serão suscitadas aqui, relacionadas ao nosso objeto de estudo - o aprendizado da docência universitária de professores bacharéis -, torna-se necessário tecer algumas considerações. A universidade exerce funções primordiais, responsabilidades diversas e enfrenta desafios. Connell (2000 apud ZABALZA, 2004, p. 35) situa a instituição universitária no complexo mundo atual atribuindo-lhe quatro responsabilidades específicas: (1) documentação, o que implica manter sua natureza como arcano de conhecimentos de todo tipo. A universidade não só aparece como o berço do saber, mas como centro de armazenamento desses saberes, aos quais se pode recorrer quando se desejar ou precisar; (2) rede virtual de informação, o que acarreta a utilização dos mais variados sistemas e suportes de comunicação, que permitem a maior distribuição possível do conhecimento, de maneira que possa chegar aos possíveis usuários, seja qual for sua localização geográfica ou sua condição financeira; (3) inovação, de forma que as universidades se transformem em focos permanentes de progresso técnico e social. Nesse sentido, devem ser capazes de fazer render ao máximo a autonomia e a disponibilidade de recursos; e (4) crítica sobre os usos e abusos do poder (em suas diversas manifestações e em diversos âmbitos) e/ou dos processos de perda de identidade individual e social.

\section{Como se sentem} os docentes frente às exigências impostas? Como se organizam e se colocam dentro desse contexto cada vez mais incerto?
Zabalza (2004) evidencia aspectos pertinentes referentes à formação como função básica da docência universitária e, ainda, em relação ao que significa a formação nesse contexto e de que maneira essa concepção de formação influencia o desenvolvimento das atividades dos docentes na universidade.

Dessa forma, é evidente que os impactos referentes a todas essas responsabilidades incidem sobre os professores, o que suscita as seguintes reflexões: como se sentem os docentes frente a todas as exigências que lhes são impostas? Como se organizam e se colocam dentro desse contexto cada vez mais incerto? Que formações podem contribuir para o enfrentamento desses desafios? Esses questionamentos estão diretamente relacionados à problemática de nossa 
investigação acerca de como ocorre o aprendizado da docência de professores bacharéis. A partir dessas ponderações, examinamos os desafios da universidade frente às demandas que se apresentam nesse cenário.

De acordo com Torres (2014, p. 74), "a universidade como instituição social de ensino surgiu com o desafio de consolidar um conhecimento científıco, em uma época em que esse tipo de saber era considerado como profano e remoto".

Ao estabelecermos relações com a docência, é possível considerar que práticas pedagógicas alinhadas à perspectiva conservadora são "sagradas", visto serem validadas pelos docentes e por seus pares, portanto difíceis de serem alteradas, sobretudo porque a docência universitária não constitui, comumente, objeto de reflexões, discussões ou mesmo de questionamentos. No ensino superior, a cultura ainda é pautada pela ideia de que quem sabe, sabe ensinar.

Defendemos que é preciso romper com essa cultura do "ensino porque sei" e dar início à cultura do "ensino porque sei e sei ensinar" (MELO, 2007, p. 32). Essa compreensão indica, invariavelmente, a necessidade de reflexões permanentes sobre o que é e como se faz a docência universitária, ou seja, quais as intencionalidades das práticas pedagógicas, no contexto de processos formativos permanentes.

A universidade como instituição social de ensino surgiu com 0 desafio de consolidar um conhecimento científico, em uma época em que esse saber era considerado profano e remoto
Para que as universidades atinjam os objetivos a que se propõem, considerando as políticas públicas que as resguardam, sustentam e orientam, são necessários enfrentamentos de conflitos e posicionamentos de grupos gestores, que, embora sejam transitórios (em média os mandatos são de quatro anos no mínimo e oito anos no máximo), acabam imprimindo suas marcas, conforme a ideologia com que cada grupo gestor se identifica. Portanto, é no movimento do processo histórico vivenciado pelas universidades que inúmeras transformações ocorreram. Enfatizamos que a finalidade da universidade deve estar associada à sua função social e jamais desarticulada dos pilares relacionados ao ensino, à pesquisa e à extensão, fundamentais para pensar a universidade na perspectiva de formação dos docentes bacharéis.

\section{A universidade como contexto do trabalho docente}

As universidades são prioritariamente instituições de ensino, pesquisa e extensão, e por conseguinte têm responsabilidades sociais para com as comunidades nas quais estão inseridas. Contudo, desde que as primeiras foram criadas no Brasil, são tantos os desafios que enfrentam que seus objetivos muitas vezes estiveram submetidos a imposições externas, na maioria das ocasiões decorrentes de políticas com foco no atendimento aos interesses do mercado, e não na prática de ensino, pesquisa e extensão.

Para Severino (2008, p. 75), "comprometida com o conhecimento, a universidade precisa estar comprometida também, por decorrência, com a extensão e a pes- 
quisa, tanto quanto com o ensino". Mas nos perguntamos como esses objetivos podem ser alcançados se, cada vez mais, a universidade está subordinada à lógica do capital, que é constantemente alterada.

O cenário específico em que se encontra a sociedade brasileira é aquele desenhado por um intenso e extenso processo de globalização econômica e cultural, conduzido pela expansão da economia capitalista, que se apoia política e ideologicamente no paradigma neoliberal.

Por isso, é uma tendência mundial que vai impondo a todos os países a minimização do Estado, a total priorização da lógica do mercado na condução da vida social, o incentivo à privatização generalizada, a defesa do individualismo, do consumismo, da competitividade, da iniciativa privada. No que diz respeito à educação, prevalece a teoria do capital humano, ou seja, a da preparação de mão de obra para o mercado de trabalho (SEVERINO, 2008, p. 76-77).

Assim, o referido autor destaca que os desafıos das universidades públicas não se diferem, de modo geral, dos problemas enfrentados por toda a educação pública em seus diferentes níveis e modalidades, sendo que os conflitos e dilemas perpassam a realidade social brasileira contemporânea, marcada pelo

[...] confronto entre uma educação pautada nas premissas da teoria do capital humano e uma Educação que se quer identificada com a teoria da emancipação humana, entre uma educação que se coloca a serviço do mercado e uma outra que se quer a serviço da construção de uma condição de existência mais humanizada, onde o trabalho é uma mediação essencial do existir histórico das pessoas e não um mero mecanismo da produção para o mercado (SEVERINO, 2008, p. 87).

Esses desafios são atribuídos aos dilemas enfrentados, muitas vezes não superados, em função da contradição que há entre o atendimento da universidade à lógica do mercado e à lógica da emancipação humana. Dessa forma, a identidade institucional toma novas diretrizes e

alguns fatores conjunturais de ordem estrutural acabaram por decretar novos rumos para a educação superior e a universidade no Brasil [...] um processo de democratização/expansão, privatização (relação público-privado) e massificação da educação superior; uma mudança na identidade institucional das universidades e no padrão de gestão da educação superior, dentre outros (VIEIRA, 2007, p. 1).

O trabalho do professor é destacado e a formação desse profissional passa a ser motivo de preocupação de organismos internacionais que veem nesse sujeito um elemento-chave na cadeia de produção do conhecimento necessário ao desenvolvimento de tal sociedade (MAUÉS, 2009). Nesse contexto, marcado por interesses do capital financeiro, o trabalho docente passa a ser alvo de políticas de avaliação externa, mesmo que indiretamente. 
Ao criarem padrões de controle que interferem na dinâmica pedagógica das universidades, essas políticas minimizam seu valor. Assim, o caminho percorrido pelo docente se resume arduamente a agir de forma a assegurar as exigências das políticas impostas pelo Estado regulador, o que desestabiliza a qualidade de seu trabalho:

Essa "obrigação de resultados" que hoje é imposta ao professor não leva em conta, na maioria das vezes, as questões estruturais e conjunturais que envolvem a profissão, tais como as condições de trabalho, que implicam turmas com mais de 50 alunos; falta de uma política de valorização do magistério, que inclui um plano de cargos e salários e um plano de formação continuada; formas de contratação temporária; uma política previdenciária que permita ao docente se aposentar com dignidade, entre outras questões fundamentais que deixam de ser consideradas nessas regulações que incidem sobre o trabalho docente, precarizando-o e flexibilizando-o (MAUÉS, 2009, p. 485).

Concluímos que, nesse contexto no qual as universidades se configuraram, as dificuldades e impasses enfrentados por elas e pelos docentes resultam das transformações ocorridas e das políticas instauradas na sociedade. Enfatizamos que os aspectos intelectuais que deveriam estar à frente dos objetivos das instituições de ensino se encontram separados dos objetivos mercantilistas, mas estes, de forma impositiva, ditam os rumos da educação. E todos os dilemas enfrentados pelos docentes diante dessas novas configurações impactam diretamente o seu trabalho, descaracterizando-o de sua função para atender a demandas exigidas pelo mercado.

\section{Os saberes docentes e a prática pedagógica}

A "profissão professor" é alvo de inúmeros debates e contradições, muitas vezes associada ao trabalho voluntário, ao "dom", ou mesmo a uma missão. Todas essas características reforçam a descaracterização de uma profissão que, como outra qualquer, precisa ser reconhecida e valorizada. De acordo com Costa (2005), no contexto brasileiro, a partir das reformas no campo da educação realizadas na década de 1990, a retórica acerca da profissão docente se desdobra na implementação da Lei de Diretrizes e Bases da Educação Nacional nº 9.394/96, que no artigo VI se refere aos "profissionais da Educação", gerando um amplo debate sobre a profissão professor, pois o tema da profissionalização não é uníssono, despertando grandes controvérsias em torno da condição de profissional dos docentes no contexto brasileiro (COSTA, 2005, p. 85). Ainda de acordo com a pesquisa realizada pela autora, a profissionalização é apresentada sob diferentes concepções: uns tendem a reafirmar a concretização das reformas, outros se contrapõem à sua efetivação. Dessa forma, diversos autores, tomando por base os debates a respeito dos movimentos de educadores, "apresentam a concepção de profissionalização em uma perspectiva crítica, em que se busca a construção de uma identidade profissional, a valorização da profissão e o reconhecimento enquanto profissionais da Educação" (COSTA, 2005, p. 104). 
Constata-se que as questões relacionadas à profissionalização da docência estão vinculadas diretamente a questões como formação e autonomia docente e à construção de uma identidade. De acordo com Oliveira (2013, p.61-62),

A noção de profissionalização aplicada à Educação sempre foi ambígua. [...] o uso do termo profissionalização na Educação sempre esteve vinculado ao quadro conceitual da sociologia americana das profissões, em que a profissionalização supõe não somente a prática do ofício em tempo pleno, mas também um estatuto legal que reconhece a qualificação dos seus membros como uma formação específica e a existência de associações profissionais. [...] essa profissionalização se traduz pela constituição de um patrimônio cognitivo e deontológico comum, sendo assim, as noções de profissionalidade e profissionalização são impostas no domínio da formação docente, fazendo passar do plano social ao das práticas profissionais e pedagógicas.

Ainda conforme Oliveira (2013), o conceito de profissionalização está intimamente vinculado aos processos de formação, portanto estão em constante interface. Sendo assim, a formação inicial e continuada, considerada um dos pilares da valorização docente, tem sido objeto de disputa de diferentes segmentos.

O professor, ao assumir as funções profissionais inerentes ao cargo em uma universidade federal, o faz a partir de um concurso público que exige dele pós-graduação em sua área de atuação. No entanto, essa exigência não implica diretamente que ele tenha uma formação pedagógica específica para a docência, o que constitui uma contradição, pois os saberes específicos da pedagogia são essenciais, conforme indica Gonçalves (2015, p. 14):

Para o exercício da docência no Ensino Superior não existe exigência legal de qualquer formação nessa direção. Entretanto, espera-se que o professor participe da elaboração do projeto pedagógico do Curso, saiba construir objetivos adequados ao perfil do egresso desejado e natureza dos conteúdos programáticos, bem como fazer planos de ensino e planos de aula, aplicar metodologias e estratégias apropriadas, avaliar a aprendizagem, entre muitas outras atividades especificas relativas ao ensino.

Diante do exposto, confirmarmos que a atuação na docência exige diversos saberes inerentes à profissão, e o que se constata é que muitos profissionais advindos de áreas especializadas do bacharelado e que atuam na docência não apresentam formação específica para essa atividade. Apesar de existirem professores que empreendem práticas pedagógicas exitosas, conseguindo mobilizar e construir saberes que provêm de várias fontes - como influência de professores no decorrer da trajetória formativa, reflexões entre pares, afinidade com questões pedagógicas -, a formação profissional para a docência é essencial. 
Para Stano e Fernandes (2015, p. 45),

[...] há falta de conhecimento e formação aos docentes universitários, que em geral fazem sua formação na área específica de uma área de conhecimento, em que as condições próprias, teóricas e técnicas do ensino não são abordadas. [...] a necessidade de se refletir o currículo como uma trajetória composta de atividades formais e informais, planejados e não planejados de significados que vão sendo construídos por professores e alunos, através da relação entre teoria e prática, entre o fazer e o saber, entre o pensar e o agir.

Nesse sentido, entende-se que a formação pedagógica permite ao professor universitário olhar para sua prática pedagógica, interpretá-la e recriá-la, tornando-a também uma fonte de aprendizagem, em uma perspectiva de mudança e inovação (JUNGES; BEHRENS, 2015).

\section{Dialogando com os dados}

Em relação ao exercício da docência antes de assumirem essa função na universidade, constatamos que 11 já lecionavam previamente a prestarem concurso para a UFU e quatro não tinham essa experiência. As respostas informadas nos questionários apontam para um índice significativo de docentes que já lecionavam antes de se tornarem professores na universidade. Em relação aos aspectos da formação profissional, reconhecemos que o professor constrói seus saberes a partir de diversas fontes, dessa forma, uma das perguntas do questionário referiu-se às contribuições possibilitadas pelos cursos realizados por eles em relação ao fazer docente.

A princípio, sobre o curso de graduação ter-lhes proporcionado uma boa formação teórico-prática, obtivemos, em todos os 15 questionários respondidos, a confirmação de que sim, de modo que os docentes consideram importantes as contribuições advindas de suas formações iniciais. Em seguida, solicitamos outras informações, a fim de analisar de que forma o curso de graduação contribuiu.

Pedimos aos professores que apontassem os aspectos dessa formação que considerassem mais fortes, assim como as fragilidades. Entre as contribuições que julgaram importantes, houve especial predomínio quanto ao aprofundamento de conteúdos da formação básica, dos quais o aprendizado de matemática, estatística e programação foram destacados.

Em relação às contribuições da formação tanto na graduação quanto na pós-graduação, 11 responderam que sim, que a formação nesses dois níveis contribuiu para suas atuações na docência. Dessa forma, reconhecemos a valorização por parte do docente quanto a esse processo relevante de construção dos conhecimentos científicos. É evidente a ênfase dada aos conteúdos, à docência e à pesquisa como sinônimos. Reconhecemos esses conceitos como distintos, pois conforme já destacamos, a docência é uma profissão complexa e, consequentemente, impli- 
ca um conjunto de conhecimentos profissionais que articulem diferentes saberes: pedagógicos, da área específica e os da experiência.

Sendo assim, o professor, ao desenvolver sua prática pautada nos saberes docentes, terá condições de organizar os conteúdos de suas aulas de forma a subsidiar o processo de aprendizagem de seus alunos.

A atividade de ensino, no sentido de uma práxis pedagógica, é de natureza diferente da atividade de pesquisa científica. Sobretudo porque o ensino, ao ser subsidiado pela pesquisa e por ocorrer a partir da articulação com ela, indica ainda mais a necessidade de uma base científica que possibilite ao professor bacharel construir subsídios teórico-metodológicos que favoreçam sua prática docente. A docência engloba todos esses processos, o que demonstra a dimensão ampla e complexa dos processos de ensino-aprendizagem. Uma das perguntas fundamentais para esta pesquisa é sobre a motivação dos magistrados na escolha da profissão.

Constatamos que o termo vocação foi citado por alguns deles, o que reforça o processo de desprofissionalização da docência
Constatamos que o termo vocação foi citado por alguns deles, o que reforça o processo de desprofissionalização da docência, já citado nesta pesquisa. Sendo assim, se o magistério é considerado "vocação" e/ou "dom", qualquer um poderá realizar a docência sem nem mesmo ter formação para tal. Um dado que nos chamou atenção se refere ao fato de a maioria dos professores terem afirmado que escolheram a docência para realizar pesquisa. Destacamos, como expõe Almeida (2012, p. 62), que "os concursos de ingresso são claramente para professor, o que evidentemente pressupõe a atividade docente. No entanto, ela não é, em muitos casos, o fator que os atrai e os leva a decidir-se por trabalhar nessas instituições". Reafirmamos que a formação permanente dos docentes poderá contribuir para o exercício de práticas pedagógicas pautadas na reflexão-ação, ou seja, uma práxis pedagógica que tenha a pesquisa como princípio formativo da docência.

As práticas pedagógicas que os docentes vivenciaram e que consideram marcantes estão relacionadas aos professores que os influenciaram positivamente e têm em comum aspectos como: aulas mais dinâmicas, atividades interessantes, projetos práticos e atividades inovadoras.

Os registros dos professores indicam, como aspectos negativos que ainda estão presentes em suas memórias, principalmente a falta de planejamento e de organização das aulas, o que compromete o processo de ensino-aprendizagem. Além disso, demonstram ter consciência de que a primazia de aulas expositivas, com a utilização de slides, pouco contribui para o aprendizado dos estudantes. Sobre a relevância da formação didático-pedagógica, 13 dos docentes responderam que a consideram importante e dois a enxergam como irrelevante, o que é incoerente com outras respostas apresentadas no questionário por parte desses docentes.

Ao serem indagados sobre a importância da formação didático-pedagógica, parte dos professores a considera importante. Respostas como "Importante, não obri- 
gatória", "Acho que pode dar subsídios, mas não é essencial" e "Nossa formação é como pesquisador, não como professor" demonstram que esses professores não reconhecem a formação didático-pedagógica como importante. No entanto, em outras respostas fica explícito o uso desses conhecimentos, ou mesmo as consequências e fragilidades que poderão ser sanadas, caso tenham um aprofundamento científico relativo aos saberes profissionais da docência.

Também obtivemos respostas em que os professores afirmam que esse conhecimento deveria ser trabalhado, todavia com foco nos cursos de exatas. Com relação à formação pedagógica, e por não reconhecerem a complexidade de aspectos que envolvem a docência (dimensões social, econômica, cultura e política), as respostas indicam que os professores esperam "cursos rápidos", atividades práticas, ou seja, não compreendem que teoria e prática são indissociáveis e que são os fundamentos teóricos que viabilizam a reflexão crítica sobre a prática pedagógica.

Nesse sentido, a concepção de formação contínua dos docentes é pautada na compreensão de que "cursos rápidos", "mais práticos" e de "curta duração" podem resolver os problemas imediatos da prática pedagógica. Reconhecemos que, ao assumirem profissionalmente a docência sem os conhecimentos pedagógicos inerentes à profissão, os docentes demonstraram que aprenderam o ofício a partir de suas práticas cotidianas. Embora a experiência seja um fator importante, que contribui para que os professores construam modos de ser e estar na profissão, ela é insuficiente, dada a complexidade de fatores, aspectos e dimensões que envolvem a docência.

Destacamos a defesa de que os saberes pedagógicos, além de essenciais à prática do professor, sustentam ações para a superação de eventuais necessidades e dificuldades a serem enfrentadas.

\section{Considerações finais}

A pesquisa teve o objetivo de investigar como ocorre o aprendizado da docência por professores bacharéis que atuam nos cursos de Sistemas de Informação e Ciência da Computação da Universidade Federal de Uberlândia. Esta investigação teve por base a análise dos projetos pedagógicos dos dois cursos, teses e dissertações dos últimos cinco anos e dados obtidos por meio de um questionário, analisado à luz de referenciais bibliográficos sobre formação docente, especificamente dos professores bacharéis.

O estudo bibliográfico permitiu compreender a trajetória histórica das universidades no Brasil, além das políticas públicas que se referem a criação e manutenção dessas instituições, das exigências a elas impostas, os dilemas e as dificuldades enfrentados. A análise nos permitiu compreender a universidade em sua historicidade e totalidade, como espaço de atuação profissional dos docentes, um espaço que é permeado por contradições, principalmente quanto ao sentido formativo da universidade. Há claramente dois projetos em disputa: um compreende a universidade como organização com compromissos marcados pelo atendimento ao capital, ou 
seja, seu sentido formativo incide na formação de capital humano; outro, que defendemos, é o projeto de universidade que a compreende como uma instituição que tem compromissos sociais com a formação humana. Os objetivos formativos assumidos nessa perspectiva se referem à emancipação, ao desenvolvimento do pensamento crítico e criativo e à expressão da liberdade de pensamento e concepções.

É o projeto de universidade que a compreende como uma instituição que tem compromissos sociais com a formação humana
Ao recuperarmos o percurso histórico da universidade e dos cursos pesquisados, foi possível compreender o contexto social, político e econômico em que os mesmos se configuraram. Portanto, analisar a constituição da docência em uma perspectiva crítico-reflexiva implica considerar que é na universidade que os docentes realizam a sua práxis, em um movimento dialético com suas trajetórias individuais e coletivas, em interface com a história da instituição e os desafios a serem enfrentados.

Verificamos nos projetos pedagógicos dos cursos a ênfase nos conhecimentos técnicos e científicos, marcados pelo compromisso com a formação profissional de seus estudantes. Um currículo que ainda é fragmentado, em que as disciplinas são estruturadas de modo a atender as Diretrizes Curriculares Nacionais para os cursos de bacharelado, portanto não constituem espaço formal de formação pedagógica. Ao discutirmos os conceitos de saberes, formação e desenvolvimento profissional, entre outros, como conhecimentos determinantes para o exercício da docência, destacamos a importância de uma base de conhecimentos científicos que devem sustentar as práticas pedagógicas.

Defendemos a necessidade de posssiblitar e consolidar processos formativos permanentes, dialógicos e colaborativos que contribuam para uma formação docente que de fato produza transformações nas práticas pedagógicas dos professores. Processos formativos que permitam construir conhecimentos profissionais da docência, que Ihes resguardem a superação das possíveis dificuldades e do dilemas enfrentados no cotidiano das aulas, conforme as adversidades relatadas nos questionários respondidos.

No que se refere à especificidade da formação docente dos professores bacharéis, ou seja, como aprendem a ser professores, evidenciamos que essa não é sistematizada e, portanto, ainda é insuficiente, sobretudo pela omissão dos cursos de pós-graduação (mestrado e doutorado), que não abordam temas relacionados aos saberes pedagógicos. Verificamos que os docentes bacharéis que atuam no ensino superior não possuem uma formação voltada para os conhecimentos pedagógicos, porém nas respostas dos questionários ficou clara a relevância desses saberes para sua atuação. Uma das contradições que emergiu da análise foi: embora reconheçam as contribuições da formação inicial e contínua e o valor da formação didático-pedagógica, inclusive manifestando o desejo de participarem de ações formativas, destacaram várias fragilidades, assim como, em alguns registros, negaram a relevância desses saberes. Ou seja, nas respostas apresentadas, parte dos docentes declara a relevância de práticas formativas vivenciadas em algum momento da carreira e en- 
fatiza modelos de práticas exitosas ao fazer referência a professores que participaram de sua formação, com essas práticas sendo munidas de saberes pedagógicos específicos. Porém, ao ser questionada sobre a relevância de uma formação voltada para saberes específicos da prática docente, afırma que esta não é essencial para atuarem como professores.

Reconhecemos, nos dados construídos, os saberes da experiência como essenciais para a atuação profissional desses docentes, práticas resultantes de experiências reconhecidas como positivas vivenciadas na condição de estudantes. Umas das questões apresentadas no questionário se referia à motivação dos docentes na escolha da profissão. Foram mencionadas a satisfação de ensinar e a oportunidade de empreender pesquisas. Entretanto, foi possível verificar em algumas respostas que os docentes não reconhecem o tripé ensino-pesquisa-extensão, pois o compreendem com vertentes desconectadas uma da outra. Assumimos que as três partes estão correlacionadas, indicando a necessidade de envolvimento e valorização de cada uma delas.

Um dos desafios cotidianos é a necessidade de estimular o interesse dos estudantes pelo conteúdo, ou seja, a preocupação constante dos magistrados reside no desafio de lidar com estudantes cada vez mais desmotivados e despreparados, precisando superar as fragilidades formativas oriundas da educação básica.

A análise nos possibilitou apresentar algumas proposições para o enfrentamento das demandas relacionadas ao aprendizado da docência de professores bacharéis:

- Fortalecer a pedagogia universitária pautada na valorização do ensino de graduação;

- Incentivar a construção de uma cultura formativa de professores na universidade pautada em práticas colaborativas e dialógicas, sistematizadas a partir das necessidades concretas dos docentes e priorizando os saberes pedagógicos;

- Institucionalizar políticas de formação e desenvolvimento profissional docente;

- Estimular a criação de espaços coletivos de discussão de problemas, dilemas e dificuldades enfrentados no cotidiano universitário;

- Criar uma política institucional de acolhimento e acompanhamento de professores que estejam ingressando na docência universitária;

- Estimular a visibilidade de práticas pedagógicas exitosas, por meio de projetos de ensino, pesquisa e extensão.

A partir das reflexões apresentadas, defendemos a sistematização dos processos formativos de professores e que os cursos de pós-graduação possam assumir a importância da formação didático-pedagógica, no sentido de possibilitar uma formação que contribua para o exercício profissional da docência. Reconhecemos que se trata de um objeto de pesquisa complexo, portanto será necessário o aprofundamento em aspectos diversos que contribuam para a profissionalização da docência universitária e, consequentemente, para a melhoria do ensino de graduação. 


\section{Referências}

ALMEIDA, Maria Isabel de. Formação do professor do ensino superior: desafios e políticas institucionais. São Paulo: Cortez, 2012.

BARDIN, Laurence. Análise de conteúdo. Lisboa: Edições 70, 1977.

CERVO, Amado Luiz; BERVIAN, Pedro Alcino; SILVA, Roberto da Silva. Metodologia científica. 6. ed. São Paulo: Pearson Prentice Hall, 2007.

COSTA, Edinilza Magalhães da. As políticas de formação dos profissionais da educação e a profissionalização docente. 2005. Dissertação (Mestrado em Educação) - Centro de Educação, Universidade Federal do Pará, Belém, 2005.

GONÇALVES, Yara Pires. Construindo a pesquisa: razões e fundamentos. In: COIMBRA, Camila Lima et al. (org.). A construção do saber docente por bacharéis no ensino superior: desafios de uma formação. Curitiba: CRV, 2015. p. 13-25.

JUNGES, Kelen dos Santos; BEHRENS, Marilda Aparecida. Prática docente no ensino superior: a formação pedagógica como mobilizadora de mudança. Perspectiva, Florianópolis, v. 33, n. 1, p. 285-317, 2015.

MARQUEZ, Amanda Cristina Teagno Lopes; PIMENTA, Selma Garrido. É possível formar professores sem os saberes da Pedagogia? - uma reflexão sobre docência e saberes. Metalinguagens, São Paulo, n. 3, p. 135-156, maio 2015.

MAUÉS, Olgaízes. Regulação educacional, formação e trabalho docente. Estudos em Avaliação Educacional, São Paulo, v. 20, n. 44, p. 473-492, 2009.

MELO, Geovana Ferreira. Tornar-se professor: a formação desenvolvida nos cursos de Física, Matemática e Química da Universidade Federal de Uberlândia. 2007. Tese (Programa de Pós-Graduação em Educação) - Faculdade de Educação, Universidade Federal de Goiás, Goiânia, 2007.

NEVES, Luis José. Pesquisa qualitativa - características, usos e possibilidades. Caderno de Pesquisas em Administração, São Paulo, v. 1, n. 3, 1996.

OLIVEIRA, Dalila Andrade. As políticas de formação e a crise da profissionalização docente: por onde passa a valorização? Revista Educação em Questão, Natal, v. 46, n. 32 , p. $51-74,2013$. 
PAULO NETTO, José. Introdução ao estudo do método de Marx. São Paulo: Expressão Popular, 2011.

TORRES, Alda Roberta. A pedagogia universitária e suas relações com as políticas institucionais para a formação de professores da educação superior. 2014. Tese (Doutorado em Educação) - Faculdade de Educação, Universidade de São Paulo, São Paulo, 2014.

SEVERINO, Antônio Joaquim. O ensino superior brasileiro: novas configurações e velhos desafios. Educar em Revista, Curitiba, n. 31, p. 73-89, 2008.

STANO, Rita de Cássia M. T; FERNANDES, Sandra Faria. O currículo e suas configurações: das práticas de ensino à qualidade da Educação. In: COIMBRA, Camila Lima et al. (org.). A construção do saber docente por bacharéis no ensino superior: desafios de uma formação. Curitiba: CRV, 2015. p. 43-57.

VIEIRA, Regina Beatriz Bevilacqua. Educação superior no contexto nacional: políticas, tensões e desafios. [S. I.: s. n.], 2007. Disponível em: https://files.cercomp. ufg.br/weby/up/65/o/politicas_ppgfe.pdf. Acesso em: 29 out. 2018.

ZABALZA, Miguel A. 0 ensino universitário: seu cenário e seus protagonistas. Porto Alegre: Artmed, 2004. 